\title{
The Effect of Sintering Temperature on Phase Evolution and Sintering Mechanism of Ceramic Proppants with $\mathrm{CaCO}_{3}$ Addition
}

\author{
Mei Qin ${ }^{a}\left(\mathbb{D}\right.$, Yuming Tian ${ }^{a, b^{*}}$, Huilan Hao ${ }^{a}$, Guomin $\mathrm{Li}^{a}$, Yi Zhou ${ }^{a}$, Yaqiao Wu ${ }^{a}$, Pinbo Bai ${ }^{c}$ \\ ${ }^{a}$ School of Materials Science and Engineering, Taiyuan University of Science and Technology, \\ Taiyuan 030024, Shanxi Province, PR China \\ ${ }^{b}$ Shanxi Engineering Vocational College, Taiyuan 030009, Shanxi Province, PR China \\ ${ }^{c}$ Changqing Fracturing Proppant Co. Ltd, Yangquan 045200, Shanxi Province, PR China
}

Received: October 31, 2019; Revised: January 8, 2020; Accepted: January 20, 2020

\begin{abstract}
Low-cost ceramic proppants were successfully prepared from natural bauxite and solid waste coal gangue via $\mathrm{CaCO}_{3}$ additive. $40 \mathrm{wt} \%$ of bauxite in raw materials was replaced by coal gangue, which significantly reduced the manufacturing costs. The apparent density, bulk density, acid solubility and breakage ratio of the proppant sintered at different temperatures were systematically investigated. The phase composition and morphological structure were determined using X-ray diffraction (XRD) and scanning electron microscopy (SEM). The results show that the amount of liquid phase affected the solid phase reaction velocity by changing sintering mechanism. When the sintering temperature was $1350{ }^{\circ} \mathrm{C}$, the optimum size of the mullite crystal particles and the optimum amount of the liquid phase were observed and the samples exhibited the best performance.
\end{abstract}

Keywords: Ceramic proppants, crystal growth, sintering temperature, mullite, mechanism.

\section{Introduction}

Hydraulic fracturing is an important technique to enhance oil and gas production, especially in low permeability oil and gas wells. Aim at maintaining the long-term conductivity in the process of oil and gas production, the hydraulic fracturing process involves injecting fluid containing proppants at a sufficient rate and pressure to break down the rock; The proppants remain in the fractures and hold them open after the hydraulic pressure is removed. Ceramic proppants are the most widely used type among fracturing proppants due to their excellent performances, such as good sphericity and roundness, high crush resistance, and good corrosion resistance compared with quartz sands ${ }^{1}$. Moreover, ceramic proppants are much cheaper than resin-coated quartz sand proppants ${ }^{2}$. However, ceramic proppants have a higher density and are more costly than quartz sands due to high proportion of bauxite in raw materials. Ma et al. ${ }^{2}$ prepared ceramic proppants using 92 $\mathrm{wt} \%$ bauxite and the samples sintered at $1400^{\circ} \mathrm{C}$ possessed the lowest breakage ratio of $2.2 \%$ under $52 \mathrm{MPa}$ closed pressure. Zhao et al. ${ }^{3}$ fabricated ceramic proppants with 93 wt $\%$ calcined bauxite, which exhibited better performance with a breakage ratio of $3.22 \%$ under $52 \mathrm{MPa}$ closed pressure sintered at $1355^{\circ} \mathrm{C}$. However, the expense of natural bauxite has risen significantly due to over-exploitation of bauxite ore, resulting in increasing the manufacturing costs of ceramic proppants. Therefore, it is important to find out materials that can partially replace the bauxite. In addition, a high apparent density can cause the proppants to accumulate at the crack initiation point, which would lead to unfavorable conductivity ${ }^{4}$. Meanwhile, proppants with large bulk density, which require high viscosity fracturing fluid to delivery, increase significantly the transportation $\operatorname{costs}^{5}$. Consequently,

*e-mail: tym1818@163.com it is quite urgent to develop low-cost, low-density proppants and to further improve the breakage resistance.

Coal gangue refers to the solid waste generated during coal mining and beneficiation and accounts for $10-15 \%$ of coal production ${ }^{6}$. The cumulative stockpiles of coal gangue in Shanxi province in China amounted to 829 million tons at the end of $2009^{7}$. This large amount of coal gangue not only occupied a large land area, but also brought significantly serious air, water, and soil pollution ${ }^{8}$. Thus, the comprehensive utilization of coal gangue is urgent and important with regard to environmental protection. In order to effectively utilize coal gangue, Zhang et al. ${ }^{7}$ systematically investigated the correlation between the composition and performance of coal gangue after calcination. Regardless of the mineral content, coal gangue as a by-product of coal production generally contains high amounts of silica and alumina ${ }^{9-10}$, which are necessary ingredients for preparing ceramic proppants. In addition, other metallic compounds of the coal gangue contributed to lower sintering temperature. The characteristics of coal gangue make it suitable for use as a partial replacement for bauxite. To the best of our knowledge, no study has been reported adding more than $30 \mathrm{wt} \%$ coal gangue as raw material and using $\mathrm{CaCO}_{3}$ as an additive to prepare ceramic proppants. The purpose of using coal gangue is to lower the costs and $\mathrm{CaCO}_{3}$ is added to decrease the sintering temperature.

In this study, low-cost, high-strength ceramic proppants were prepared from natural bauxite and solid waste coal gangue as main raw materials and $\mathrm{CaCO}_{3}$ as an additive. The effects of the sintering temperature on the apparent density, bulk density, breakage ratio, and acid solubility were thoroughly investigated. The fracture property, phase evolution in the sintering process and sintering mechanism were determined. 


\section{Experimental procedure}

\subsection{Raw materials}

Natural bauxite and coal gangue from Yangquan in Shanxi province in China were used as the raw materials and lime carbonate $\left(\mathrm{CaCO}_{3} \geq 98 \%\right.$ ) was added as a sintering additive. Chemical composition of them was displayed in Table 1.

\subsection{Preparation}

The weight ratio of natural bauxite, coal gangue, and lime carbonate was 55:40:5. First, the mixtures were weighed and ground with a planetary ball mill to the desired size, and then were moved to a strong mixing machine (R02, Eirich Co. Ltd. Germany) to form spherical bodies with the addition of water. Second, the bodies were dried at $100{ }^{\circ} \mathrm{C}$ for $2 \mathrm{~h}$ in a drying box (DH-101-2BS, Tianjin Central Experiment Furnace Co. Ltd. China). After drying, the green bodies were screened through the sieves of $0.91 \mathrm{~mm}-0.71 \mathrm{~mm}$ in diameter. Third, the obtained particles were sintered in a high temperature box-type sintering furnace (KF1700, Bo Yun Tong Instrument Technology Co. Ltd. Nanjing, China) at different temperatures $\left(1250{ }^{\circ} \mathrm{C}, 1300{ }^{\circ} \mathrm{C}, 1350{ }^{\circ} \mathrm{C}\right.$, $1400^{\circ} \mathrm{C}, 1450{ }^{\circ} \mathrm{C}$ ) in air for $2 \mathrm{~h}$ at a heating rate of $5^{\circ} \mathrm{C} / \mathrm{min}$. Finally, the proppants were cooled to $400{ }^{\circ} \mathrm{C}$ at a cooling rate of $5^{\circ} \mathrm{C} / \mathrm{min}$ by furnace cooling. The cooled proppants were passed through sieves of 20/40 mesh (aperture size of $0.85-0.43 \mathrm{~mm}$ ) to obtain the finished product.

\subsection{Measurement and Characterization}

The bulk density, the apparent density, the breakage ratio, and the acid solubility were determined based on the Chinese Petroleum and Gas Industry Standard (SY/T 5108-2014). The bulk density was calculated using the following formula, $\rho_{b}=\frac{m_{b}}{V_{b}}$, where $\mathrm{m}_{\mathrm{b}}$ is the weight of one unit sample and $\mathrm{V}_{\mathrm{b}}$ is volume containing stacking voids besides volume of one unit sample. The apparent density was determined by the Archimedes immersion method using water as medium and expressed by the following formula, $\rho_{a}=\frac{m_{p} \rho_{l}}{m_{f+1}+m_{p}-m_{f+l+p}}$ where $\mathrm{m}_{\mathrm{p}}$ is the mass of the samples in density bottle to the level, $\mathrm{m}_{\mathrm{f}+1}$ is the mass of the density bottle with liquid up to the level, $\mathrm{m}_{\mathrm{f}+1+\mathrm{p}}$ is the mass of the density bottle with the liquid and the samples to the level, and $\rho_{1}$ is the density of the liquid used in the measurement. Breakage ratio was calculated using the following formula: $\eta=\frac{m_{c}}{m_{0}} \times 100 \%$, where $\mathrm{m}_{\mathrm{c}}$ is the weight of the crushed samples and $\mathrm{m}_{0}$ is the weights of the samples before testing. The acid solubility was tested in a $12 \mathrm{wt} \% \mathrm{HCl}$ and $3 \mathrm{wt} \% \mathrm{HF}$ acid solution in a water bath at $66{ }^{\circ} \mathrm{C}$ for $30 \mathrm{~min}$. The acid solubility was obtained using the following formula: $S=\frac{m_{s}-m_{a}}{m_{s}} \times 100 \%$, where $\mathrm{m}_{\mathrm{s}}$ and $\mathrm{m}_{\mathrm{a}}$ were the obtaining weight of the samples before and after treating with the acid solution.

The phase compositions were identified by X-ray powder diffraction (MiniFlex600; Rigaku Co. Ltd. Japan) using Ni filtered $\mathrm{Cu} K \alpha$ radiation $(\mathrm{K} \alpha=0.154 \mathrm{~nm})$ with a scan speed of $6 \% \mathrm{~min}$. The morphology was investigated using a cold field emission scanning electron microscope (FESEM) (S-4800; Hitachi, Tokyo, Japan).

\section{Results and Discussion}

Figure 1 shows XRD patterns of the raw materials. The main crystal phases of the natural bauxite were diaspore (AlO $(\mathrm{OH}), \mathrm{PDF}$ no. 05-0355) and kaolin $\left(\mathrm{Al}_{2} \mathrm{O}_{3} \cdot 2 \mathrm{SiO}_{2} \cdot 2 \mathrm{H}_{2} \mathrm{O}\right.$, PDF no.14-0164). For the coal gangue, diffraction peaks of quartz $\left(\mathrm{SiO}_{2}, \mathrm{PDF}\right.$ no.46-1045) as main phase, followed by kaolin and illite $\left(\mathrm{K}_{2} \mathrm{O} \cdot 3 \mathrm{Al}_{2} \mathrm{O}_{3} \cdot 6 \mathrm{SiO}_{2} \cdot \mathrm{nH}_{2} \mathrm{O}\right.$, PDF no.29-1496), and pyrite ( $\mathrm{FeS}_{2}$, PDF no.43-1340) representing the major impurity were indexed.

The XRD patterns of the specimens sintered at different temperatures are presented in Figure 2. The crystalline phase contained corundum $\left(\mathrm{Al}_{2} \mathrm{O}_{3}\right.$, PDF no.46-1212), mullite $\left(3 \mathrm{Al}_{2} \mathrm{O}_{3} \cdot 2 \mathrm{SiO}_{2}\right.$, PDF no. 15-0776), and a certain amount of anorthite $\left(\mathrm{CaO} \cdot \mathrm{Al}_{2} \mathrm{O}_{3} \cdot 2 \mathrm{SiO}_{2}, \mathrm{PDF}\right.$ no. 41-1486). Nevertheless, the diffraction peak intensities of specimens at different temperatures were distinctly different. Compared with sintered at $1250{ }^{\circ} \mathrm{C}$, the diffraction peaks of corundum decreased and that of mullite enhanced greatly at $1300^{\circ} \mathrm{C}$, indicating appearance of large quantities of mullite. The trend of sample sintered at $1350{ }^{\circ} \mathrm{C}$ is the same as that at $1300^{\circ} \mathrm{C}$. When the sintering temperature rose from $1350{ }^{\circ} \mathrm{C}$ to $1450{ }^{\circ} \mathrm{C}$, the diffraction peaks of mullite decreased slightly. The peak intensity of anorthite always kept constant. It was inferred the

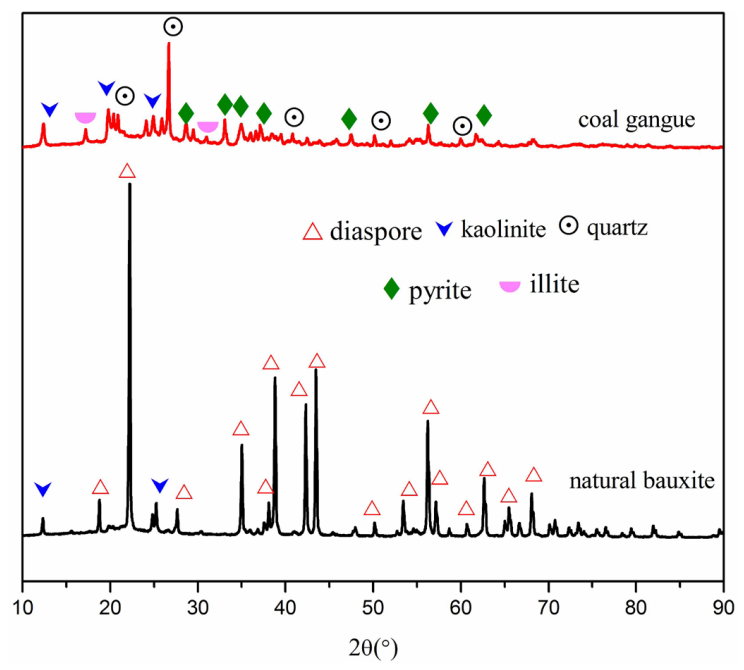

Figure 1. XRD patterns of the raw materials.

Table 1. Chemical compositions of the raw materials (wt $\%$ ).

\begin{tabular}{lcccccc}
\hline & $\mathrm{Al}_{2} \mathrm{O}_{3}$ & $\mathrm{SiO}_{2}$ & $\mathrm{Fe}_{2} \mathrm{O}_{3}$ & $\mathrm{TiO}_{2}$ & $\mathrm{~K}_{2} \mathrm{O}$ & L.O.I \\
\hline Bauxite & 74.3 & 6.0 & 2.0 & 2.7 & & 15.0 \\
\hline Coal gangue & 27.4 & 30.7 & 8.1 & 2.7 & 1.2 & 29.9 \\
\hline
\end{tabular}


Table 2. The crystal phase contents of the samples (wt\%).

\begin{tabular}{cccc}
\hline Temperature $\left({ }^{\circ} \mathrm{C}\right)$ & Corundum & Mullite & Anorthite \\
\hline 1250 & 59.80 & 15.72 & 24.40 \\
\hline 1300 & 54.64 & 18.48 & 26.87 \\
\hline 1350 & 52.79 & 20.42 & 26.79 \\
\hline 1400 & 58.07 & 15.51 & 26.42 \\
\hline 1450 & 59.77 & 12.18 & 28.05 \\
\hline
\end{tabular}

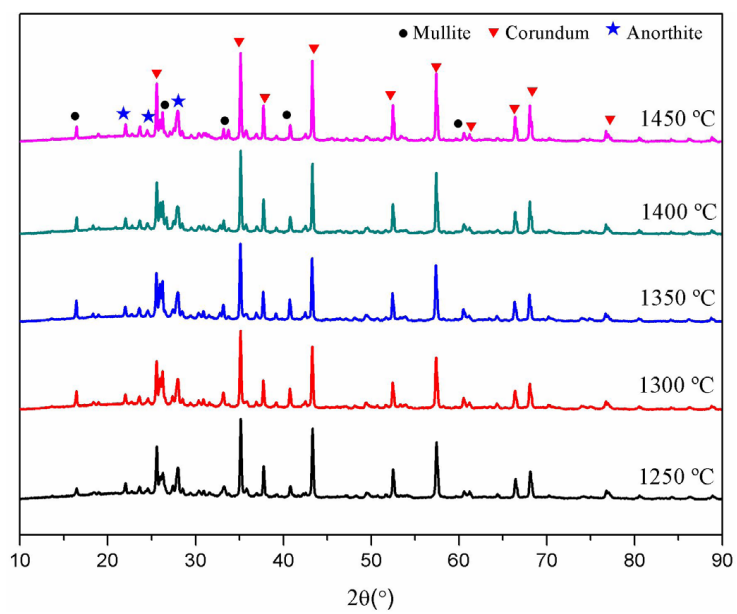

Figure 2. XRD patterns of the specimens sintered at different temperatures.

content of $\mathrm{CaO}$ from the thermal decomposition of $\mathrm{CaCO}_{3}$ did not change due to the fixed addition of $5 \mathrm{wt} \% \mathrm{CaCO}_{3}$. In order to clarify the trend of crystal grains, a quantitative analysis was performed. The results were displayed in Table 2. It can be seen that the crystal contents calculated based on XRD diffraction analysis in accordance with the above analysis.

Comparison with Figure 1, the diffraction peaks of quartz disappeared in Figure 2. It may be that quartz existed in an amorphous state after sintering. In addition, there was no diffraction peaks of the other phases of the raw materials identified. The results indicated that the phases of the raw materials transformed into new phases in sintering process. Because the $\mathrm{OH}$-stretching bands in kaolin, illite, and diaspore underwent dehydroxylation at high temperatures due to thermally unstable. This led to the structural evolution and the formation of new oxides. The detailed reactions are defined as follows:

$$
\begin{aligned}
& \mathrm{Al}_{2} \mathrm{O}_{3} \cdot 2 \mathrm{SiO}_{2} \cdot 2 \mathrm{H}_{2} \mathrm{O} \rightarrow \mathrm{Al}_{2} \mathrm{O}_{3} \cdot 2 \mathrm{SiO}_{2}+2 \mathrm{H}_{2} \mathrm{O} \\
& 3\left(\mathrm{Al}_{2} \mathrm{O}_{3} \cdot 2 \mathrm{SiO}_{2}\right) \rightarrow 3 \mathrm{Al}_{2} \mathrm{O}_{3} \cdot 2 \mathrm{SiO}_{2}+4 \mathrm{SiO}_{2} \\
& \mathrm{AlO}(\mathrm{OH}) \rightarrow \mathrm{Al}_{2} \mathrm{O}_{3} \text { (amorphous) } \rightarrow \gamma-\mathrm{Al}_{2} \mathrm{O}_{3} \rightarrow \alpha-\mathrm{Al}_{2} \mathrm{O}_{3} \\
& 3 \mathrm{Al}_{2} \mathrm{O}_{3}+2 \mathrm{SiO}_{2} \rightarrow 3 \mathrm{Al}_{2} \mathrm{O}_{3} \cdot 2 \mathrm{SiO}_{2} \\
& \mathrm{Al}_{2} \mathrm{O}_{3}+\mathrm{L} \text { (liquid phase) } \rightarrow \mathrm{CaO} \cdot \mathrm{Al}_{2} \mathrm{O}_{3} \cdot 2 \mathrm{SiO}_{2}+3 \mathrm{Al}_{2} \mathrm{O}_{3} \cdot 2 \mathrm{SiO}_{2}
\end{aligned}
$$

Kaolin can be made into metakaolin when it is dehydrated between $450^{\circ} \mathrm{C}$ to $600^{\circ} \mathrm{C}^{11}$, and then the primary mullite was generated from the phase transformation of metakaolin above $1000^{\circ} \mathrm{C}^{12}$; This is defined in Equation 1 (Eq. is the abbreviation of equation) and Equation 2. As can be seen in Equation 3, the diaspore underwent dehydroxylation to form $\mathrm{Al}_{2} \mathrm{O}_{3}$ in the amorphous state between 400 and $700{ }^{\circ} \mathrm{C}^{12}$. After the reaction with amorphous $\mathrm{SiO}_{2}$ to form the secondary mullite at $1250{ }^{\circ} \mathrm{C}^{13}$, the remaining amorphous corundum (defined in Equation 4) would be further converted into $\alpha-\mathrm{Al}_{2} \mathrm{O}_{3}$. Finally, the thermal decomposition of calcium carbonate produced calcium oxide. Subsequently, the $\mathrm{CaO}-\mathrm{Al}_{2} \mathrm{O}_{3}-\mathrm{SiO}_{2}$ ternary system was formed; the formation of anorthite was related to the reaction defined in Equation 5. In addition, compared with the $\mathrm{Al}_{2} \mathrm{O}_{3}-\mathrm{SiO}_{2}$ binary system, the $\mathrm{CaO}-\mathrm{Al}_{2} \mathrm{O}_{3}-\mathrm{SiO}_{2}$ ternary system phase diagram exhibited lower eutectic point. The existence of the liquid phase was conducive to the diffusion of ions such as $\mathrm{Al}^{3+}$ and $\mathrm{Si}^{4+}$, which was closely related to the growth of the mullite grains ${ }^{14}$.

The SEM images of the cross-section of the specimens sintered at different temperatures after determining the breakage ratio are presented in Figure 3. In Figure 3a (sintered at $1250{ }^{\circ} \mathrm{C}$ ), there was a lot of corundum with a plate-like shape, a few lath-shaped anorthite, and scaly-shaped particles representing the primary mullite phase. Sintered at $1300^{\circ} \mathrm{C}$ (Figure 3b), acicular crystalline grains with secondary mullite characteristics significantly increased. This was consistent with the XRD results, which demonstrated that the mullite greatly increased and the alumina slightly decreased. Obtained at $1350{ }^{\circ} \mathrm{C}$ (Figure $3 \mathrm{c}$ ), rod-shaped mullite occurred, and the grains were interlaced in a network structure. Moreover, plate-like alumina and lath-shaped anorthite were scattered around the mullite grains. As seen in Figure 3d (sintered at $1400^{\circ} \mathrm{C}$ ), the mullite grains grew up and crystal boundaries between the mullite grains began to become obscure due to the additional generation of the liquid phase, which was beneficial for crystal growth. When the temperature was up to $1450^{\circ} \mathrm{C}$, the proppants overheated and the particles bonded together. Figure $3 \mathrm{e}$ (sintered at $1450^{\circ} \mathrm{C}$ ) shows the glass phase tightly wrapped corundum, anorthite and mullite grains. The abundant liquid phase caused abnormal growth of the mullite and melting of the crystals ${ }^{14}$. The cracks of the samples at $1250^{\circ} \mathrm{C}$ in Figure $3 \mathrm{f}$ indicated that the fractures of the proppants under the action of an external force began in the pores. It is well known that high porosity reduces the load area and concentrated the stress at the edges of pores ${ }^{15}$.

The apparent density and bulk density as a function of the sintering temperature are shown in Figure 4. According to concept, the internal pores of particle are seen as a part of particle volume for the apparent density. In contrast, the 


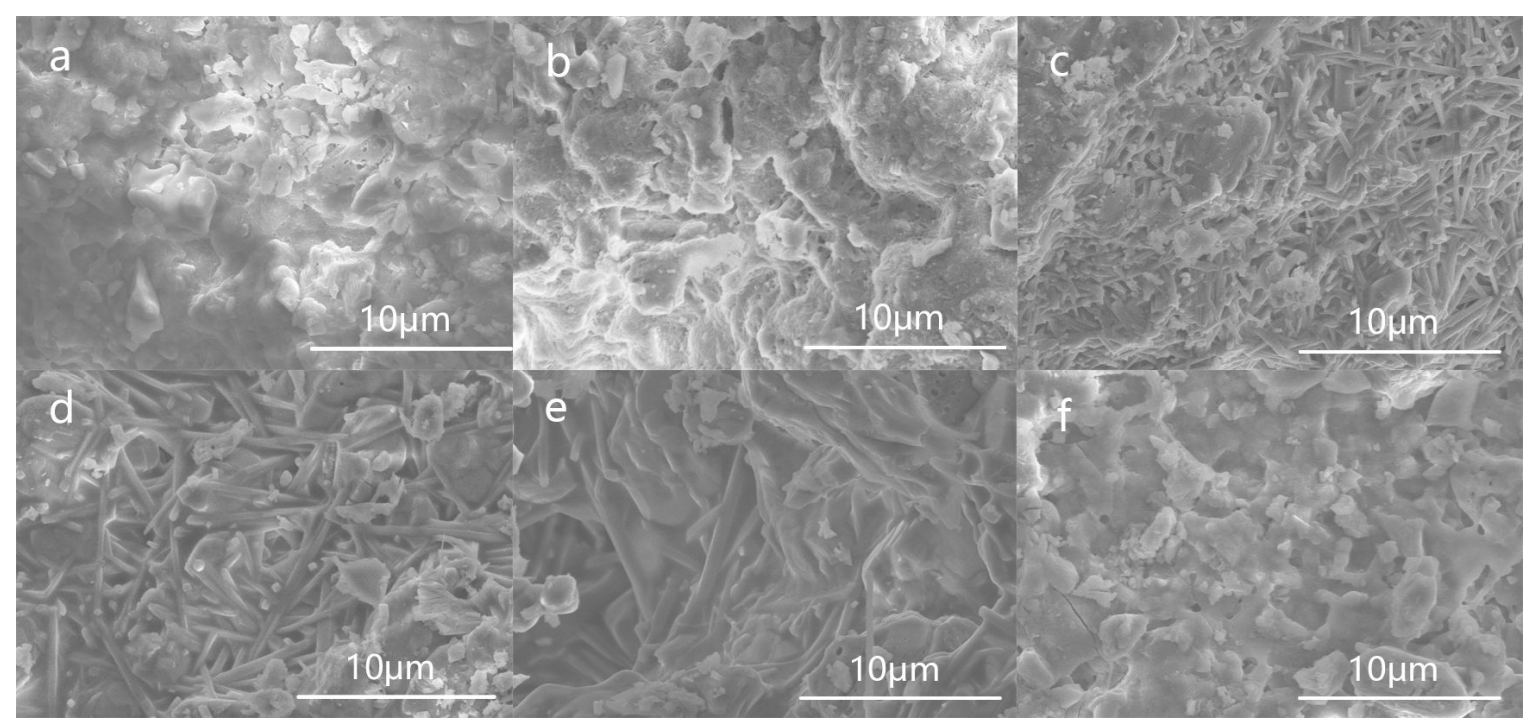

Figure 3. SEM images of the specimens sintered at (a) $1250^{\circ} \mathrm{C}$, (b) $1300^{\circ} \mathrm{C}$, (c) $1350^{\circ} \mathrm{C}$, (d) $1400^{\circ} \mathrm{C}$, (e) $1450^{\circ} \mathrm{C}$ and (f) the fractured section of the samples sintered at $1250^{\circ} \mathrm{C}$.

volume corresponding to bulk density also includes open pores of particles and voids generated by many particles packing as a unit (named stacking pores) besides internal pores. As the sintering temperature rose from $1250^{\circ} \mathrm{C}$ to $1350{ }^{\circ} \mathrm{C}$, the apparent density remained nearly steady, whereas the bulk density displayed obvious increasing trend, and then both of them decreased from $1350{ }^{\circ} \mathrm{C}$ to $1450{ }^{\circ} \mathrm{C}$. The phenomenon below $1350{ }^{\circ} \mathrm{C}$ indicated that the sum of open porosity and stacking porosity reduced based on constant apparent density. We can infer that stacking porosity also decreased, because only the reduction of open porosity is not enough to cause a significant increase in bulk density. It is well known that volume shrinkage caused by sintering densification could result in reduction of stacking pores and volume of particles itself. Therefore, increase of the internal porosity could maintain the stability in apparent density. The reason for the decrease in density of samples sintered above $1350^{\circ} \mathrm{C}$ was that with the generation of more liquid phases, not only the open pores and internal pores were filled, but the volume shrinkage caused by sintering reduces the stacked voids and volume itself.

The crushing resistance and acid corrosion resistances are significant factors to assess the performance of ceramic proppants. As can be seen from Figure 5, the breakage ratio and acid solubility of the samples first decreased and then increased with enhanced temperature. The trend was opposite to that of the bulk density. The maximum bulk density $\left(1.42 \mathrm{~g} / \mathrm{cm}^{3}\right)$, minimum breakage ratio $(8.41 \%)$, and lower acid solubility $(8.6 \mathrm{wt} \%)$ occurred at $1350^{\circ} \mathrm{C}$.

Taking into account all the experimental results, it can be clearly seen that sintering temperature has effects on sintering mechanism, which further affected solid phase reaction velocity and crystal grains growth. In Figure 4 and Figure 5, the turning point in performances of samples displayed at $1350{ }^{\circ} \mathrm{C}$. The main model of mass transfer was diffusion mass transfer due to generation of little liquid phase below $1350^{\circ} \mathrm{C}$. In the sintering process, the sintering temperature

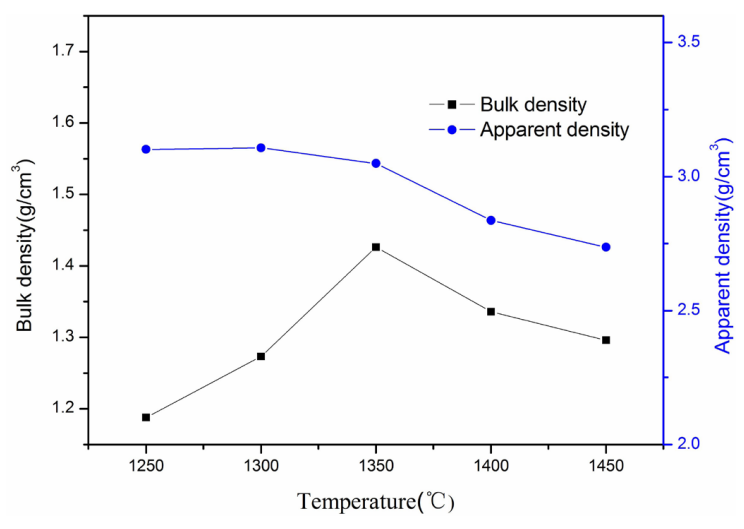

Figure 4. Apparent density and bulk density with sintering temperatures.

affected the diffusion coefficient, and then further effected diffusion velocity, which ultimately determined reaction rate. As can be seen in Figures 3a, 3b and 3c, a few liquid phases cannot fill all of the pores via the model of diffusion mass transfer. Therefore, the diffusion speed was slower. Abundant liquid phases were generated above $1350^{\circ} \mathrm{C}$, and the main model of mass transfer converted into flow mass transfer. The liquid phases filled the open pores and internal pores, resulting in reduction of porosity and improvement of densification, which reconfirms the results of Figure $3 \mathrm{~d}, 3 \mathrm{e}$. Therefore, reaction rate significantly accelerated. The cracks in Figure $3 \mathrm{f}$ can be explained by the basis of Griffith theories ${ }^{16}$, the edges of pores would cause stress concentration under the external force, the cracks began to expand at the edges of pores and result in fracture.

The development of crystal structure is another influence factor for the mechanical properties, and it is also affected by sintering temperature. Temperature enhancing promoted the generation of liquid phase and reduction of viscosity, which would lead to a fundamental change in mass 


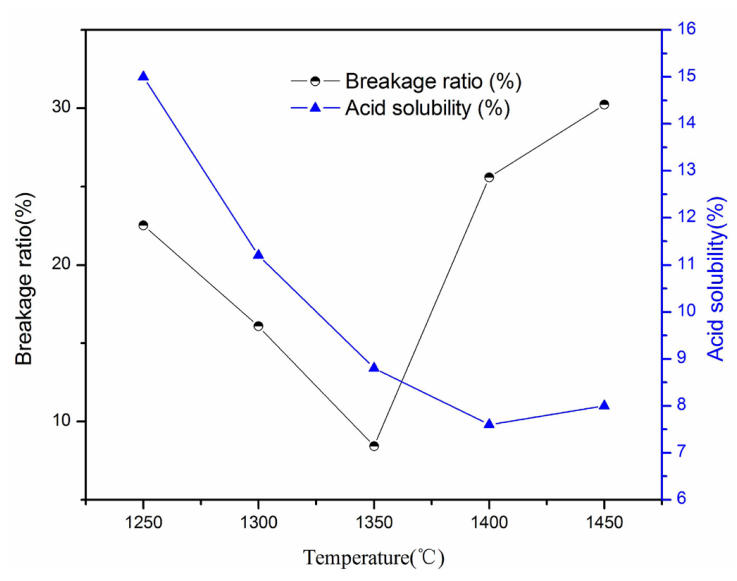

Figure 5. Breakage ratio at $52 \mathrm{MPa}$ pressure and acid solubility with sintering temperatures.

transfer mode. Growth rate of mullite grains were slower below $1350{ }^{\circ} \mathrm{C}$ due to diffusion mass transfer. When the temperature exceeded $1350{ }^{\circ} \mathrm{C}$, the grains growth became higher. The major reason was that generation of abundant liquid phases caused the flow mass transfer to become the main model of mass transfer, which promoted obviously the diffusion rate. Meanwhile, Capillary force caused by surface tension captured gaps between grains and accelerated the crystal growth. In addition, the reduction of liquid phase viscosity decreased diffusion resistance, which was beneficial for the growth of mullite grains. Sintered at $1450{ }^{\circ} \mathrm{C}$, the excessive liquid phase was generated and the crystals exhibited abnormal growth. The results were consistent with the SEM image shown in Figure 3. The generation of liquid phases promoted densification of samples, which was correlated with strength and acid solubility. However, the excessive glass phase would weaken the relationship of crystal grains and affected the strength of samples ${ }^{17}$ and glass phase easily dissolved in acid. Thereby the properties of samples underwent a change in Figure 5.

\section{Conclusions}

In this study, the performance of low-cost ceramic proppants with $5 \mathrm{wt} \% \mathrm{CaCO}_{3}$ as an additive was explored at different sintering temperatures. The amount of liquid phase eventually resulted in changes of the mode of mass transfer from diffusion mass transfer to flow mass transfer. Flow mass transfer promoted rapidly the growth of mullite grains and the densification of the samples. The optimum size of the mullite crystal grains and liquid phase amount occurred at $1350^{\circ} \mathrm{C}$. As the sintering temperature increased above $1350^{\circ} \mathrm{C}$, the mullite crystal grains exhibited abnormal growth and the amount of liquid phase was excessive. The proppants sintered at $1350{ }^{\circ} \mathrm{C}$ exhibited the maximum bulk density of $1.42 \mathrm{~g} / \mathrm{cm}^{3}$ and the lowest breakage ratio of $8.41 \%$ under $52 \mathrm{MPa}$ closed pressure, which met the requirements of the Chinese Petroleum and Gas Industry Standard (SY/T 5108-2014). The higher quality of the proppants and the cheaper raw material make them suitable for use as fracturing proppants in future applications.

\section{Acknowledgements}

This work was supported by the Major Science and Technology Project in Shanxi Province [20181101001]; the Talents Training Project of Shanxi Graduate Joint Training Base in China [2017JD33, 2018JD34]; Shanxi Province Science Foundation for Youths [201801D221119]; Key Research and Development (R\&D) Projects of Shanxi Province [201803D121027]; The Basic Research Project in Shanxi Province [201801D221121]; The Science and Technology Carrier and Platform Project in Jinzhong City [P182002]; the Shanxi Province of Key Subjects Construction in China and the Collaborative Innovation Centre of Shanxi Province Key Basic materials in China.

\section{References}

1. Hao JY, Ma HQ, Feng X, Gao YF, Wang KY, Tian YM, et al. Microstructure and fracture mechanism of low density ceramic proppants. Mater Lett. 2018;213:92-4.

2. Ma HQ, Tian YM, Zhou Y, Li GM, Wang KY. Effective reduction of sintering temperature and breakage ratio for a low-cost ceramic proppant by feldspar addition. Int J Appl Ceram Technol. 2018;15:191-6.

3. Zhao JZ, Liu ZL, Li YM. Preparation and characterization of low -density mullite -based ceramic proppant by a dynamic sintering method. Mater Lett. 2015;152:72-5.

4. Kulkarni MC, Ochoa OO. Mechanics of light weight proppants: A discrete approach. Compos Sci Technol. 2012;72:879-85.

5. Ma XX, Tian YM, Zhou Y, Wang KY, Chai YS, Li ZG. Sintering temperature dependence of low-cost, low-density ceramic proppant with high breakage resistance. Mater Lett. 2016;180:127-9.

6. Liu HB, Liu ZL. Recycling utilization patterns of coal mining waste in China. Resour Conserv Recycling. 2010;54:1331-40.

7. Zhang YY, Xu L, Seetharaman S, Liu LL, Wang XD, Zhang ZT. Effects of chemistry and mineral on structural evolution and chemical reactivity of coal gangue during calcination: towards efficient utilization. Mater Struct. 2015;48:2779-93.

8. Deng DH, Cen WL. Environmental effect of coal gangue stack area. China Mining Magazine. 1999;18:87-91.

9. Zhou CC, Liu GJ, Yan ZC, Fang T, Wang RW. Transformation behavior of mineral composition and trace elements during coal gangue combustion. Fuel. 2012;97:644-50.

10. Xiao HM, Ma XQ, Liu K. Co-combustion kinetics of sewage sludge with coal and coal gangue under different atmospheres. Energy Convers Manage. 2010;51:1976-80.

11. Kakali G, Perraki T, Tsivilis S, Badogiannis E. Thermal treatment of kaolin: the effects of mineralogy on the pozzolanic activity. Appl Clay Sci. 2001;20(1-2):73-80.

12. Chakraborty AK. DTA study of preheated kaolinite in the mullite formation region. Thermochim Acta. 2003;398:203-9.

13. Lee WE, Souza GP, McConville CJ, Tarvornpanich T, Iqbal Y. Mullite formation in clay-derived vitreous ceramics. J Eur Ceram Soc. 2008;28:465-71.

14. Wu XL, Huo ZZ, Ren Q, Li HH, Lin F, Wei TY. Preparation and characterization of ceramic propants with low density and high strength using fly ash. J Alloys Compd. 2017;702:442-8.

15. Liu ZL, Zhao JZ, Li YM, Zeng ZH, Mao JC, Peng Y. Lowtemperature sintering of bauxite-based fracturing proppants containing $\mathrm{CaO}$ and $\mathrm{MnO}_{2}$ additives. Mater Lett. 2016;171:300-6.

16. Gong JH, editor. Fracture of brittle solids: Lawn B. Beijing: Higher Education Press; 2010. p.3-10.

17. Kong XC, Tian YM, Chai YS, Zhao PF, Wang KY, Li ZG. Effects of pyrolusite additive on the microstructure and mechanical strength of corundum-mullite ceramics. Ceram Int. 2015;41:4294-300. 